\title{
Additive and interactive effects of word frequency and masked repetition in the lexical decision task
}

\author{
SACHIKO KINOSHITA \\ Macquarie University, Sydney, Australia
}

\begin{abstract}
In previous studies, additive effects of masked repetition and word frequency on lexical decision latency have been reported. This additive pattern was replicated in Experiment 1 with the use of lowfrequency words (range, 1-7 per million) selected at random. In contrast, in Experiment 2, in which low-frequency words known to be familiar to the subjects were used, the masked repetition priming effect was greater for low-frequency than for high-frequency words. It is suggested that the absence of an interaction between masked repetition and frequency observed in previous studies and in the present Experiment 1 was due to the fact that very-low-frequency words often have an unstable representation in the subjects' lexicon and, consequently, sometimes fail to produce repetition priming effects in full.
\end{abstract}

In the masked priming procedure developed by Forster and Davis (1984), a briefly presented prime (in lowercase) is preceded by a forward mask (\#\#\#\#) and followed immediately by a target (in uppercase) so that subjects are generally unaware of the prime. Because subjects are not consciously aware of the prime, it is generally assumed that the effect of the prime on target processing reflects an automatic process. One of the findings noted by Forster and Davis (1984) with the use of this procedure is that the effects of masked repetition and word frequency are additive. This pattern has been taken as one of the benchmark findings that need to be explained by any model of word recognition.

The absence of an interaction between the effects of masked repetition and those of word frequency has been replicated many times (for a list of references, see Table 1). Recently, however, the empirical status of the additive pattern has been called into question. Both Davis (1999) and Bodner and Masson (1997) noted that in previous studies the magnitude of the masked repetition priming effect for low-frequency words was generally numerically greater than that of the effect for high-frequency words, and suggested that the absence of a statistically significant interaction in the individual studies may have been due to a lack of power. In accordance with this suggestion, Masson and Bodner (2003) reported that when a "stronger manipulation of word frequency" (p. 72) was used, Bodner and Masson (2001) observed statistically significant interactions in four experiments. Specifically, they argued

\footnotetext{
This study was supported by Australian Research Council Discovery Projects Grant DP0556805 to S.K. Thanks are due Tania Malouf for research assistance and Glen Bodner, Ken Forster, and an anonymous reviewer who provided very helpful comments on an earlier version of the manuscript. Correspondence concerning this article may be addressed to S. Kinoshita, Macquarie Centre for Cognitive Science and Department of Psychology, Macquarie University, Sydney, NSW 2109, Australia (e-mail: skinoshi@maccs.mq.edu.au).
}

that the frequency range of the high-frequency words was responsible for the interaction. Whereas both Bodner and Masson (1997) and Forster and Davis (1984) used highfrequency words in the range of 40-60 occurrences per million (according to Kučera \& Francis, 1967) and found no interaction between frequency and repetition, Bodner and Masson (2001) used high-frequency words with more than 100 occurrences per million and a median frequency of about 200 per million, and found interactive effects.

The present study was motivated by this empirical controversy regarding whether the effects of masked repetition and frequency are additive or interactive. It was considered important to resolve this issue because it has implications for theories of word recognition and repetition priming.

Table 1 shows the size of masked repetition priming effects for low- and high-frequency words reported in previous studies. In all of the studies with the exception of Bodner and Masson (2001), the interaction between frequency and repetition was not significant. The studies are ordered so that those that found numerically greater repetition priming effects for low- than for high-frequency words are listed toward the end of the table. It is of interest to note that the characteristics of low-frequency words appear to be different in the studies that showed greater repetition benefit for low-frequency words than in those that did not. Specifically, whereas the studies reporting the additive pattern (Forster \& Davis, 1984; Rajaram \& Neely, 1992 ) used words that were of very low frequency (e.g., 1-2 per million) and/or associated with high error rates, the studies showing an interactive pattern (Bodner \& Masson, 2001; Forster \& Davis, 1991, Experiment 5; Sereno, 1991) used low-frequency words of $1-10$ per million, and these low-frequency words were associated with lower error rates. Although a difference of 1-2 per million and 1-10 per million seems like a minor one, there are reasons to suspect that it may be important. Gernsbacher (1984) suggested that the high error rates in a lexical decision task 
Table 1

Size of Masked Repetition Priming Effects (MRPEs, in Milliseconds) for Low-Frequency (LF) and High-Frequency (HF) Words, and the Characteristics of Words in Previous Studies

\begin{tabular}{|c|c|c|c|c|}
\hline \multirow[b]{2}{*}{ Source } & \multirow[b]{2}{*}{ MRPE } & \multicolumn{2}{|c|}{ Error Rate } & \multirow{2}{*}{$\begin{array}{l}\text { Frequency Range } \\
\text { (per Million) }\end{array}$} \\
\hline & & Repeated & Control & \\
\hline \multicolumn{5}{|c|}{ Forster \& Davis (1984), Experiment 1} \\
\hline LF & 38 & .153 & .212 & $1-2$ \\
\hline $\mathrm{HF}$ & 45 & .029 & .045 & $40-60$ \\
\hline $\mathrm{LF}-\mathrm{HF}$ & -7 & & & \\
\hline \multicolumn{5}{|c|}{ Forster, Davis, Schoknect, \& Carter (1987), Experiment 4} \\
\hline LF & 25 & .136 & .218 & $<11$ \\
\hline $\mathrm{HF}$ & 34 & .032 & .028 & $>200$ \\
\hline $\mathrm{LF}-\mathrm{HF}$ & -9 & & & \\
\hline \multicolumn{5}{|c|}{ Forster et al. (1987), Experiment 1} \\
\hline $\mathrm{LF}$ & 66 & .063 & .175 & $6-9$ \\
\hline HF & 61 & .013 & .075 & $>60$ \\
\hline $\mathrm{LF}-\mathrm{HF}$ & 5 & & & \\
\hline \multicolumn{5}{|c|}{ Rajaram \& Neely (1992), Experiment 1 ("nonstudied" items) } \\
\hline LF & 37 & .239 & .279 & $1-2$ \\
\hline $\mathrm{HF}$ & 30 & .042 & .092 & $40-69$ \\
\hline $\mathrm{LF}-\mathrm{HF}$ & 7 & & & \\
\hline \multicolumn{5}{|c|}{ Bodner \& Masson (1997), Experiment 1} \\
\hline LF & 45 & .156 & .168 & $1-2$ \\
\hline $\mathrm{HF}$ & 29 & .002 & .007 & $40-60$ \\
\hline $\mathrm{LF}-\mathrm{HF}$ & 16 & & & \\
\hline \multicolumn{5}{|c|}{ Forster \& Davis (1991), Experiment 5} \\
\hline LF & 72 & .083 & .193 & $<10(M=5.7)$ \\
\hline $\mathrm{HF}$ & 54 & .044 & .120 & $>100$ \\
\hline $\mathrm{LF}-\mathrm{HF}$ & 18 & & & \\
\hline \multicolumn{5}{|c|}{ Sereno (1991), Experiment 1 (“different" control) } \\
\hline LF & 64 & .070 & .110 & $M=7$ \\
\hline HF & 40 & .015 & .035 & $M=175$ \\
\hline $\mathrm{LF}-\mathrm{HF}$ & 24 & & & \\
\hline \multicolumn{5}{|c|}{ Sereno (1991), Experiment 1 ("opposite" control) } \\
\hline LF & 72 & .070 & .105 & $M=7$ \\
\hline HF & 42 & .015 & .015 & $M=175$ \\
\hline $\mathrm{LF}-\mathrm{HF}$ & 30 & & & \\
\hline \multicolumn{5}{|c|}{$\begin{array}{l}\text { Bodner \& Masson (2001), averaged across Exps. 2A, 2B, 3, and } 6 \\
\text { (reported in Masson \& Bodner, 2003) }\end{array}$} \\
\hline LF & 69 & .064 & .114 & $1-10$ \\
\hline $\mathrm{HF}$ & 37 & .018 & .034 & $100-1,000$ \\
\hline $\mathrm{LF}-\mathrm{HF}$ & 32 & & & $(M d n=200)$ \\
\hline
\end{tabular}

(LDT) for words in the very-low-frequency range may not be due to the subject's attempt to trade accuracy for speed, but may reflect the fact that the subject actually did not know the word. In support of this view, Paap, Johansen, Chun, and Vonnahme (2000) gave subjects a pencil-andpaper LDT (i.e., without the pressure to make speeded decisions as in the standard LDT) and found that a sizeable proportion of low-frequency words $(26.8 \%)$ in the range of $1-5$ per million failed to be recognized as words. Kinoshita and Mozer (2006) used a similar procedure and found that for low-frequency words in the range of 1-10 per million, $11.5 \%$ failed to be recognized as words. Furthermore, even when the words were correctly judged to be words, subjects were often not confident of their judgments. These findings led both Paap et al. and Kinoshita and Mozer to suggest that many words in the very-lowfrequency range may not have stable representations in the subjects' lexicons. Perhaps, then, this was responsible for the null interaction between frequency and masked repetition, rather than a weak manipulation of frequency, as Masson and Bodner (2003) suggested. A corollary of this view is that a reliable interaction would be observed if low-frequency words that are familiar to subjects were used. In Experiment 1, we tested the first prediction, and in Experiment 2 we tested the second.

\section{METHOD}

\section{Subjects}

A total of 48 Macquarie University students (24 in each of Experiments 1 and 2) participated for course credit.

\section{Design}

The LDT was used in both Experiments 1 and 2. Each experiment constituted a 2 (frequency: high vs. low) $\times 2$ (prime type: repetition vs. unrelated) factorial design, with both factors manipulated within subjects. The dependent variables were lexical decision latency and error rate.

\section{Materials}

The critical stimulus materials used in both experiments were 48 high-frequency words, 48 low-frequency words, and 96 orthographically legal nonwords matched on the number of neighbors $(\mathrm{N}$, as defined by Coltheart, Davelaar, Jonasson, \& Besner, 1977) to the word stimuli. All items were five letters long. The high-frequency words were identical in the two experiments and ranged in frequency from 103 to 665 occurrences per million, with a mean of 233 according to the Kučera and Francis (1967) corpus. (According to HAL, the range is 20,364-388,384 and the mean, 94,428; see Burgess \& Livesay, 1998.)

In Experiment 1, the only criterion for selecting the low-frequency words was frequency range (according to Kučera \& Francis, 1967, range $=1-7$ per million, $M=2.94$; according to HAL, range $=46$ $7,178, M=1,945)$. In the untimed paper-and-pencil lexical decision test used by Kinoshita and Mozer (2006), these items produced an error rate of $11.5 \%$, and a mean confidence rating of 2.24 on a scale of -3 (very confident it is a made-up word) to +3 (very confident it is a word). (For individual word data, see Kinoshita \& Mozer, 2006.) $\mathrm{N}$ ranged from 0 to 13 for the high-frequency words $(M=$ 4.77) and from 0 to 8 for the low-frequency words $(M=3.02)$. The nonwords were selected using the ARC Nonword Database (Rastle, Harrington, \& Coltheart, 2002, available at www.maccs.mq.edu $. \mathrm{au} / \sim \mathrm{nwdb})$.

In Experiment 2, the low-frequency words (range $=1-20$ occurrences per million, $M=7.81$ according to Kučera \& Francis, 1967; range $=540-65,844, M=6,379$ according to HAL) were selected on the basis of their having a minimum familiarity rating of 490 on a scale of 100-700 based on the MRC Psycholinguistic Database (Coltheart, 1981, www.psy.uwa.edu.au/MRCDataBase/uwa_mrc .htm). In the untimed paper-and-pencil lexical decision test used by Kinoshita and Mozer (2006), these words produced an error rate of $1.65 \%$ and a confidence rating of 2.89 . The low-frequency words ranged in $\mathrm{N}$ from 0 to $10(M=3.90)$. The words are listed in the Appendix.

Each item type (high-frequency words, low-frequency words, and nonwords) was divided into two sets. For each experiment, two list versions were constructed for the purpose of counterbalancing assignment of sets to the two prime types - namely, repetition primes and unrelated primes. The unrelated primes were other items from the same set, so that each target was paired with an unrelated prime of the same lexical class, length, and frequency class (for words) as the target (e.g., the unrelated nonword prime nunch was paired with the nonword target DWAME), as in Bodner and Masson (1997, Experiment 1). Thus, each target was paired with a repetition prime 
or an unrelated prime so that each target was seen by a subject only once, and across every 2 subjects it was paired once with a repetition prime and once with an unrelated prime.

Prior to each test block, the subjects were given 8 practice items and 16 initial buffer items that were representative of the items used. Practice and buffer items were selected according to the same criteria as the test stimuli. These items were not included in the analysis.

\section{Apparatus and Procedure}

The subjects were tested individually. They were seated approximately $40 \mathrm{~cm}$ in front of a 19-in. Dell Flat Trinitron monitor on which stimuli were presented. Each subject completed 192 trials presented in one block. The order of trials was random, and a different order was generated for each subject.

The subjects were instructed at the outset of each experiment that they would be presented with a series of letter strings and that their task was to decide for each item whether it was a word or a nonword, as fast and accurately as possible. They were instructed to press a key marked "+" on the response keypad for words and a key marked "-" for nonwords.

Stimulus presentation and data collection were achieved through the use of Forster and Forster's (2003) DMDX display system (Version 3.1) on a Dell Dimension 8400 computer running on an Intel Pentium 4 chip at $3.0 \mathrm{GHz}$. Stimulus display was synchronized to the screen refresh rate $(13.3 \mathrm{msec})$.

Each trial started with the presentation of a forward mask consisting of five hash marks (\#\#\#\#\#). The mask was followed first by a prime in lowercase letters for four ticks of screen refresh $(53 \mathrm{msec})$ and then by a target letter string presented in uppercase, in the center of the screen, in white Courier 10-point font against a black background. No mention was made of the presence of primes. The letter string remained on the screen until the subject's response, for a maximum of 2,000 msec. Following a $300-\mathrm{msec}$ blank screen, the next trial started. The participants were given no feedback on either latencies or error rates during the experiments.

\section{RESULTS}

For both experiments, the preliminary treatment of trials was as follows. Any trial on which a subject made an error was excluded from the latency analysis. To reduce the effects of extremely long and short latencies, the cutoff was set for each subject at $3 S D$ s from that subject's mean $\mathrm{RT}$, and latencies beyond the cutoff were replaced with the cutoff value. Word targets and nonwords were analyzed separately. Word targets were analyzed using a two-way ANOVA with prime type (repetition vs. unrelated) and frequency (high vs. low) as factors. In the subjects analysis, both prime type and frequency were within-subjects factors, and in the items analysis prime type was a withinitems factor and frequency was a between-items factor. Nonwords were analyzed using a one-way ANOVA with prime type (repetition vs. unrelated) as the factor. For nonwords, prime type was both a within-subjects and a within-items factor. An effect was considered to be significant when both the subjects and the items analyses were significant at the .05 level.

\section{Experiment 1}

The data-trimming procedure affected $1.30 \%$ of the trials. Mean lexical decision latencies and error rates in Experiment 1 are presented in Table 2.

Words. In the analysis of latency, the main effect of prime type was highly significant $\left[F_{1}(1,23)=43.32\right.$, $\left.M S_{\mathrm{e}}=682.65 ; F_{2}(1,94)=16.82, M S_{\mathrm{e}}=4,053.58\right]$. The main effect of frequency was also significant $\left[F_{1}(1,23)=\right.$ $72.66, M S_{\mathrm{e}}=2,639.80 ; F_{2}(1,94)=93.97, M S_{\mathrm{e}}=$ 4,497.40]. The two factors did not interact (both $F$ s $<$ 1.0). For error rate, only the main effect of frequency was significant $\left[F_{1}(1,23)=29.20, M S_{\mathrm{e}}=109.45 ; F_{2}(1,94)=\right.$ $\left.35.62, M S_{\mathrm{e}}=179.53\right]$. Although the main effect of prime type was significant by items $\left[F_{2}(1,94)=4.89\right.$, $\left.M S_{\mathrm{e}}=53.96\right]$, it did not reach significance by subjects $\left[F_{1}(1,23)=2.94, M S_{\mathrm{e}}=45.07\right]$. The interaction was nonsignificant (both $F \mathrm{~s}<1.0$ ).

Nonwords. There was no effect of prime type for latency (both $F_{\mathrm{S}}<1.0$ ) or for error rate $\left[F_{1}(1,23)=1.56\right.$, $\left.M S_{\mathrm{e}}=18.42, p=.22 ; F_{2}(1,95)<1.0\right]$.

\section{Experiment 2}

In Experiment 2, the data-trimming procedure affected $1.63 \%$ of the trials. Mean lexical decision latencies and error rates are presented in Table 3.

Words. In the analysis of latency, the main effect of prime type was highly significant $\left[F_{1}(1,23)=45.71\right.$, $\left.M S_{\mathrm{e}}=1,013.66 ; F_{2}(1,94)=64.37, M S_{\mathrm{e}}=1,487.86\right]$. The main effect of frequency was also significant $\left[F_{1}(1,23)=\right.$ $\left.66.58, M S_{\mathrm{e}}=526.78 ; F_{2}(1,94)=20.85, M S_{\mathrm{e}}=3,460.63\right]$, and the two factors interacted $\left[F_{1}(1,23)=12.60, M S_{\mathrm{e}}=\right.$ $\left.410.95 ; F_{2}(1,94)=6.92, M S_{\mathrm{e}}=1,487.86\right]$. The interaction reflected the fact that the repetition priming effect was greater for low-frequency words $(59 \mathrm{msec})$ than for high-frequency words $(29 \mathrm{msec})$. For error rate, only the main effect of frequency was significant $\left[F_{1}(1,23)=\right.$ $\left.14.57, M S_{\mathrm{e}}=16.98 ; F_{2}(1,94)=12.38, M S_{\mathrm{e}}=39.94\right]$. Other main and interaction effects did not reach significance $(F \mathrm{~s}<3.35, p \mathrm{~s}>.08)$.

Nonwords. In the analysis of latency, the effect of prime type was significant $\left[F_{1}(1,23)=8.95, M S_{\mathrm{e}}=\right.$ 683.74; $\left.F_{2}(1,95)=4.59, M S_{\mathrm{e}}=5,591.22\right]$. Performance on repetition trials was $23 \mathrm{msec}$ faster than performance

Table 2

Mean Lexical Decision Latencies (RTs, in Milliseconds), With Standard Errors, and Percent Error Rates (\%Error) by Prime Type in Experiment 1

\begin{tabular}{|c|c|c|c|c|c|c|c|c|}
\hline \multirow[b]{2}{*}{ Frequency } & \multicolumn{3}{|c|}{ Repetition } & \multicolumn{3}{|c|}{ Unrelated } & \multicolumn{2}{|c|}{ Priming Effect } \\
\hline & RT & $S E$ & $\%$ Error & RT & $S E$ & $\%$ Error & RT & $\%$ Error \\
\hline High & 508 & 14 & 2.3 & 540 & 16 & 3.6 & 32 & 1.3 \\
\hline Low & 594 & 21 & 12.8 & 632 & 21 & 16.1 & 38 & 3.3 \\
\hline Nonword & 648 & 23 & 11.2 & 648 & 22 & 12.8 & 0 & 1.6 \\
\hline
\end{tabular}


Table 3

\begin{tabular}{|c|c|c|c|c|c|c|c|c|}
\hline \multirow[b]{2}{*}{ Frequency } & \multicolumn{3}{|c|}{ Repetition } & \multicolumn{3}{|c|}{ Unrelated } & \multicolumn{2}{|c|}{ Priming Effect } \\
\hline & RT & $S E$ & $\%$ Error & RT & $S E$ & $\%$ Error & RT & $\%$ Error \\
\hline High & 504 & 12 & 2.8 & 533 & 12 & 3.0 & 29 & 0.2 \\
\hline Low & 527 & 12 & 4.9 & 586 & 13 & 7.3 & 59 & 2.4 \\
\hline Nonword & 667 & 20 & 10.3 & 690 & 21 & 12.4 & 23 & 2.1 \\
\hline
\end{tabular}

on unrelated trials. For error rate, the effect was nonsignificant $\left[F_{1}(1,23)=2.25, M S_{\mathrm{e}}=23.28, p=.15 ; F_{2}(1,95)=\right.$ $\left.2.05, M S_{\mathrm{e}}=101.66\right]$.

\section{DISCUSSION}

The main finding of the present study is that the observation of both interactive effects of frequency and masked repetition priming and additive effects depended on the nature of the low-frequency words. Specifically, in Experiment 1 , in which low-frequency words were selected at random (from the range of 1-7 per million), a statistically null interaction between frequency and repetition was found, replicating the pattern reported many times in previous studies (e.g., Forster \& Davis, 1984; Rajaram \& Neely, 1992). In contrast, with low-frequency words that are familiar to the subjects, Experiment 2 showed a greater masked repetition priming effect for low- than for high-frequency words.

Why was an interaction between masked repetition and frequency produced in Experiment 2 but not in Experiment 1 ? One possibility that can be easily ruled out is that the manipulation of frequency was weaker in the experiment that produced the null interaction (see Masson \& Bodner, 2003), because the size of the frequency effect was in fact numerically greater in Experiment $1(89 \mathrm{msec})$ than in Experiment $2(38 \mathrm{msec})$. The greater frequency effect observed in Experiment 1 relative to Experiment 2 is not surprising given that the subjects in the first experiment were less confident of the lexical status of a number of the low-frequency words (as is evidenced in the confidence rating data of the paper-and-pencil lexical decision test) and, hence, lexical discrimination would have been more difficult. The difficulty of discrimination is also borne out in the higher error rates observed in the (speeded) LDT with these words $(12.8 \%$ and $16.1 \%$ in the repetition and unrelated prime conditions, respectively) than in that with the familiar low-frequency words in Experiment 2 (4.9\% and $7.3 \%$, respectively).

Another possibility is that the weaker repetition priming effect observed with the low-frequency words used in Experiment 1 was an artifact of the high error rate observed with these items. The idea is that the unfamiliar low-frequency words, which would produce long latencies, are also more likely to be rejected as nonwords, and when this occurs they do not contribute to the correct latency data. Coupled with the observation that error rates were higher in the unrelated prime condition $(16.1 \%)$ than the repetition prime condition $(12.8 \%)$, it is possible that the mean (correct) latency in the unrelated prime condition was artifactually reduced because the trials that would have produced very long latencies were excluded, resulting in an underestimate of the size of the repetition priming effect. Although it cannot be ruled out entirely on logical grounds, analysis of the item data provides little evidence for this possibility. A post hoc classification of the low-frequency words in Experiment 1 into those with high $(\geq 25 \%, 11$ words) versus those with low $(<25 \%$, 37 words) error rates showed that the error rate increased more from the repetition condition $(28.8 \%)$ to the unrelated prime condition $(39.4 \%)$ for the error-prone words than for the words with low error rates (from $8.1 \%$ to $9.2 \%$ ). However, the repetition priming effect in latency was, if anything, greater for the former words relative to the latter words ( 51 vs. $42 \mathrm{msec}$ ). Therefore, it seems unlikely that the weaker repetition priming effect (in terms of latency) observed with the low-frequency words in Experiment 1 was due to the error rate artifact.

In the absence of other viable explanations, it is suggested that the absence of a frequency $\times$ masked repetition interaction in Experiment 1 was due to the fact that many of the low-frequency words did not have stable lexical representations. As was mentioned earlier, the paperand-pencil lexical decision data (Kinoshita \& Mozer, 2006) indicated that the subjects were not confident of their judgments for many of these words even when they judged them to be words. This suggests that, on some occasions, even a target correctly identified as a word (and hence contributing to the latency data) failed to access a word representation when presented as a masked prime (i.e., a repetition prime); it is as though a nonword related in form had been presented as a masked prime. The fact that priming effects produced by form-related nonword primes are smaller in magnitude than the effect produced by a repetition prime (see, e.g., Forster, Mohan, \& Hector, 2003) could explain why the repetition priming effect would be weaker when the word has an unstable representation. This account also applies to previous studies in which very-low-frequency words were used and additive effects of masked repetition and frequency were found.

It should be pointed out that subjective familiarity, the factor used as the basis for selecting the low-frequency words used in Experiment 2, is known to be correlated with a number of other factors, such as concreteness, imageability, and age-of-acquisition, to name just a few (see, e.g., Balota, Cortese, Sergent-Marshall, Spieler, \& 
Yap, 2004; Gernsbacher, 1984). ${ }^{1}$ It is therefore possible that one (or more) of these factors, rather than subjective familiarity per se, was responsible for the modulation of the frequency $\times$ repetition priming interaction. However, even if this were the case, it is not incompatible with the present stability-of-lexical-representation account, because concrete, imageable, early-acquired words are robust against the impact of brain impairment on word finding difficulty (see, e.g., Nickels \& Howard, 1995), suggesting that these factors contribute to the stability of lexical representation. The issue of which factor(s) is causally responsible for the stability of lexical representation has important theoretical implications for more than just the mechanism of masked repetition priming. For example, it is likely that the same factors also impact on the ease of vocabulary acquisition by children (learnability). The issue is beyond the scope of the present study, but it is hoped that future studies will advance understanding of how frequency and other factors impact on the stability of lexical representation.

The present findings have several practical implications when low-frequency words are used to study masked repetition priming. One obvious point is that if one wishes to study the effects of masked repetition on words, one should ensure that subjects know the words. Similar caution should be taken when conducting item-level simulations with computational models to model human data: Whether or not the model's vocabulary closely approximates the subjects' working vocabulary has consequences for how accurately the model can simulate human data. It follows from this view that, in agreement with Davis (1999) and Masson and Bodner (2003), the interactive pattern observed in Experiment 2 (in which the low-frequency words were ensured to be known to the subjects) should be viewed as the benchmark finding regarding the effects of frequency and masked repetition. Finally, there are likely to be individual differences in the stability of lexical representations, especially for words in the very-low-frequency range: More literate individuals are more likely to be familiar with these words than less literate individuals. This is borne out anecdotally by the fact that in Forster and Davis's (1984) Experiment 1, the low-frequency words from the 1-2 per million range produced high error rates $(15.3 \%-21.2 \%)$ in the undergraduate subjects tested despite the fact that the words were "judged by the experimenter to be within the working vocabulary of the typical subject" (p. 683). Since the level of literacy is expected to impact particularly on lowfrequency words, it is important to ensure that these words have a stable representation in the lexicon of the subjects in question.

In sum, the contributions of the present study lie in resolving an empirical controversy and in identifying a factor responsible for the mixed patterns of the frequency $X$ masked repetition interaction in the LDT. It is hoped that the results presented here provide a firmer basis for developing theoretical accounts of masked priming.

\section{REFERENCES}

Balota, D. A., Cortese, M. J., Sergent-Marshall, S. D., Spieler, D. H., \& YAP, M. J. (2004). Visual word recognition of single-syllable words. Journal of Experimental Psychology: General, 133, 283-316.

Bodner, G. E., \& Masson, M. E. J. (1997). Masked repetition priming of words and nonwords: Evidence for a nonlexical basis for priming. Journal of Memory \& Language, 37, 268-293.

Bodner, G. E., \& Masson, M. E. J. (2001). Prime validity affects masked repetition priming: Evidence for an episodic resource account of priming. Journal of Memory \& Language, 45, 616-647.

Burgess, C., \& Livesay, K. (1998). The effect of corpus size in predicting reaction time in a basic word recognition task: Moving on from Kučera and Francis. Behavior Research Methods, Instruments, \& Computers, 30, 272-277.

Coltheart, M. (1981). The MRC Psycholinguistic database. Quarterly Journal of Experimental Psychology, 33A, 497-508.

Coltheart, M., Davelaar, E., Jonasson, J. T., \& Besner, D. (1977). Access to the internal lexicon. In S. Dornic (Ed.), Attention and performance VI (pp. 535-555). Hillsdale, NJ: Erlbaum.

DAVIS, C. [J.] (1999). The self-organising lexical acquisition and recognition (SOLAR) model of visual word recognition (Doctoral dissertation, University of New South Wales, 1999). Dissertation Abstracts International, 62, 594. (Available at www.maccs.mq.edu.au/ colin/ thesis.zip).

DAVIS, C. J. (2003). Factors underlying masked priming effects in competitive network models of visual word recognition. In S. Kinoshita \& S. J. Lupker (Eds.), Masked priming: The state of the art (pp. 121170). Hove, U.K.: Psychology Press.

Forster, K. I., \& DAVIS, C. (1984). Repetition priming and frequency attenuation in lexical access. Journal of Experimental Psychology: Learning, Memory, \& Cognition, 10, 680-698.

Forster, K. I., \& DAVIS, C. (1991). The density constraint on formpriming in the naming task: Interference effects from a masked prime. Journal of Memory \& Language, 30, 1-25.

Forster, K. I., Davis, C., Schoknecht, C., \& Carter, R. (1987). Masked priming with graphemically related forms: Repetition or partial activation? Quarterly Journal of Experimental Psychology, 39A, 211-251.

Forster, K. I., \& Forster, J. C. (2003). DMDX: A Windows display program with millisecond accuracy. Behavior Research Methods, Instruments, \& Computers, 35, 116-124.

Forster, K. I., Mohan, K., \& Hector, J. (2003). The mechanics of masked priming. In S. Kinoshita \& S. J. Lupker (Eds.), Masked priming: The state of the art (pp. 3-38). Hove, U.K.: Psychology Press.

Gernsbacher, M. A. (1984). Resolving 20 years of inconsistent interactions between lexical familiarity and orthography, concreteness, and polysemy. Journal of Experimental Psychology: General, 113, 256-281.

Kinoshita, S., \& Mozer, M. C. (2006). How lexical decision is affected by recent experience: Symmetric versus asymmetric frequencyblocking effects. Memory \& Cognition, 34, 726-742.

KuČERA, H., \& FrANCIS, W. N. (1967). Computational analysis of presentday American English. Providence, RI: Brown University Press.

Masson, M. E. J., \& Bodner, G. E. (2003). A retrospective view of masked priming: Toward a unified account of masked and long-term repetition priming. In S. Kinoshita \& S. J. Lupker (Eds.), Masked priming: The state of the art (pp. 57-94). Hove, U.K.: Psychology Press.

Nickels, L., \& HowARD, D. (1995). Aphasic naming: What matters? Neuropsychologia, 33, 1281-1303.

PaAp, K. R., Johansen, L., Chun, E., \& Vonnahme, P. (2000). Neighborhood frequency does affect performance in the Reicher task: En- 
coding or decision? Journal of Experimental Psychology: Human Perception \& Performance, 26, 1691-1720.

Rajaram, S., \& Neely, J. H. (1992). Dissociative masked repetition priming and word frequency effects in lexical decision and episodic recognition tasks. Journal of Memory \& Language, 31, 152-182.

Rastle, K., Harrington, J., \& Coltheart, M. (2002). 358,534 Nonwords: The ARC Nonword Database. Quarterly Journal of Experimental Psychology, 55A, 1339-1362.

SERENO, J. (1991). Graphemic, associative, and syntactic priming effects at a brief stimulus onset asynchrony in lexical decision and naming. Journal of Experimental Psychology: Learning, Memory, \& Cognition, 17, 459-477.

\section{NOTE}

1. Mean concreteness ratings (based on the MRC Psycholinguistic Database; Coltheart, 1981) were 468 (45 words), 457 (14 words), and 544 (45 words) for the high-frequency words, low-frequency words in Experiment 1, and low-frequency words in Experiment 2, respectively. Mean imageability ratings were 511 (38 words), 498 (14 words), and 559 (48 words), respectively. Mean age-of-acquisition ratings were 277 (12 words), 347 ( 5 words), and 301 ( 23 words). Thus, in general, the familiar low-frequency words in Experiment 2 were more concrete, more imageable, and acquired earlier than the low-frequency words in Experiment 1.

\section{APPENDIX \\ Word Stimuli Used}

\section{High-Frequency Words Used in Experiments 1 and 2}

black, blood, bring, child, class, clear, close, death, drive, early, earth, field, final, floor, force, front, great, green, heart, heavy, hotel, house, large, later, least, leave, level, light, money, month, mouth, music, night, north, paper, party, peace, right, river, short, space, speak, stage, stand, start, story, study, table

\section{Low-Frequency Words Used in Experiment 1}

adore, aloof, amaze, barge, bland, brunt, canal, carve, chalk, cheat, chick, colon, crate, crave, drake, drone, droop, ebony, eject, fairy, filth, flare, fling, flirt, flute, goose, gouge, graft, greed, groan, groom, hinge, hoist, lucid, lunge, lurch, maple, marsh, medal, pluck, plush, poach, scald, scalp, scarf, vicar, vinyl, vowel

\section{Low-Frequency Words of High Familiarity Used in Experiment 2}

apple, apron, blush, brake, broom, chalk, cheat, clock, clown, dense, elbow, fancy, flame, float, frost, grape, gravy, hobby, jelly, juice, lemon, linen, marry, nerve, nurse, onion, peach, pedal, puppy, purse, salad, salty, shout, skate, slang, slope, smash, spear, spice, spoon, stair, steal, steam, thief, tiger, toast, towel, trash

(Manuscript received August 15, 2005;

revision accepted for publication January 4, 2006.) 